University for Business and Technology in Kosovo

UBT Knowledge Center

UBT International Conference

2018 UBT International Conference

Oct 27th, 9:00 AM - 10:30 AM

\title{
The role of community in urban regeneration Case study city of Skenderaj
}

\author{
Rineta Jashari \\ University for Business and Technology, rineta.jashari@ubt-uni.net \\ Safete Veliu \\ University for Business and Technology, safete.veliu@ubt-uni.net \\ Valdrin Tahiri \\ University for Business and Technology, vt32314@ubt-uni.net
}

Follow this and additional works at: https://knowledgecenter.ubt-uni.net/conference

Part of the Architecture Commons

\footnotetext{
Recommended Citation

Jashari, Rineta; Veliu, Safete; and Tahiri, Valdrin, "The role of community in urban regeneration Case study city of Skenderaj" (2018). UBT International Conference. 25.

https://knowledgecenter.ubt-uni.net/conference/2018/all-events/25

This Event is brought to you for free and open access by the Publication and Journals at UBT Knowledge Center. It has been accepted for inclusion in UBT International Conference by an authorized administrator of UBT Knowledge Center. For more information, please contact knowledge.center@ubt-uni.net.
} 


\title{
The role of community in urban regeneration Case study city of Skenderaj
}

\author{
Rineta Jashari ${ }^{1}$, Safete Veliu ${ }^{2}$, Valdrin Tahiri ${ }^{2}$ \\ Rineta.jashari@ubt-uni.net ; safete.veli@ubt-uni.net ; vt32314@ubt-uni.net
}

\begin{abstract}
The essence of the research is to study whether the role of community opinion within the decision-making process is a fundamental and essential factor to ensure the enhancement of the quality of urban regeneration activities. Various international researches show that community involvement can have an essential impact on quality improvement during the sustainable planning process and can lead to successful urban regeneration initiatives. Also, it emphasizes the need to integrate social elements in urban regeneration practices in order to have a different approach by socio-economic changes, and socio-spatial planning and community. In this case, the city of Skenderaj was taken as the case study in order to obtain the community's opinion regarding their decision-making in sustainable planning concerning public facilities and public spaces in the city.
\end{abstract}

Keywords: community, urban regeneration, Skenderaj, industrial zone, social aspect.

\section{Introduction}

Urban regeneration and the role of the community: Towards a community empowerment significant changes in the theoretical background of planning practice in urban regeneration and its conceptual paradigms have evolved over the last decades. A historic moment in returning the final approach reflected in the 1960s model, in a new model presented by the main ideas for identity and participation by (Jacobs, 1961) and (Davidoff, 1965). The community's importance for the urban regeneration policy has been recently discussed by (Bailey, 2012)which thoroughly assesses the phenomenon of community enterprises, that is, social enterprises involved in a geographically defined area by referring to a particular community. Bailey concluded that "The primary force of the community enterprise is that it can utilize visible social capital in local communities and use it to achieve positive results" (Bailey, 2012, p. 7). In the 1990s, there was a massive interest in the Italian culture of planning, with the experience of integrated programs (Ricci \& Avarello, 2000) culminating 
in participatory and identity-driven regeneration experiences, widely researched in Italian literature from (Magnaghi, 2000) in the production of values for the territory (Ombuen, Ricci, \& Segnalini, 2000).

Even though communities play a crucial role in urban regeneration, the assessment of their contribution is still a challenging issue. A possible approach, suggested, derives from the reprocessing of the value system involved in urban regeneration processes, It is assumed that a link is made about economic values between wealth production and social networking, provided that the concept of "value" is adequately reviewed in the context of the citizen's economy, in doing so, the paper focuses on community role and in good public participation as possible, and best, alternatives to urban regeneration.

\section{Literature review}

Urban regeneration is an attempt to renovate neighborhoods in the city by improving physical infrastructure and revitalizing local economies. The concept of urban regeneration can be interpreted in different ways, mainly depending on the country's development stage. After World War II, many Western cities sought to reduce poverty and loss through urban development policies, including providing social housing, public infrastructure, and welfare assistance. However, in the 1960s, poverty was still widespread within the inner cities, and many urban neighborhoods struggled with a high degree of crime, unemployment, and higher levels of stress (Atkinson, Combating social exclusion in Europe: The new urban policy challenge, 2000). Planners and policymakers began to review traditional approaches to urban development. As a result, in the 1970s, in western cities, the reduction and renovation of large urban projects diminished and urban regeneration appeared as an alternative to urban renewal Couch, Sykes, \& Borstinghaus, (2011).

It is claimed that residents participate in urban regeneration projects is more efficient and effective in achieving the purpose of the schemes because it helps address the most important problems perceived by residents (Dargan, 2009). Sometimes, residents are better at extracting new and innovative ideas to solve problems. Furthermore, residents 'participation can prevent existing neighbors' schemes from ignoring and strengthening schemes by drawing them into the urban regeneration process (Dargan, 2009). Another advantage of urban residents participation in urban regeneration is the prevention of social exclusion linked to unemployment, weak skills, high crime, inadequate housing, and family segregation. With this prospect, many scholars have investigated how the participation of residents affects the success of urban regeneration. (Rabbiosi, 2016) (Dargan, 2009) (Couch, Sykes, \& Borstinghaus, 2011)

The general belief is that participation is a 'good thing' for urban regeneration projects. However, some researchers have pointed out that residents are often excluded from the urban regeneration decision-making process (Atkinson, 2003). Without the redistribution of power, Arnstein argued that participation is an empty experience. In her study "A degree of community participation" she stressed that participation is about power. She suggested a typology of eight levels of participation. The two lower levels (manipulation and therapy) describe non-participation, while the top three levels (citizen 
control, delegated power, and partnership) imply an increasing degree of decision-making power.

Fainstein also stressed that values of equality, diversity, and democracy could bring better results for the city. She argued that powerless and marginalized groups in the community should be encouraged to participate in the decision-making process (Fainstein, 2014). Besides, scholars have argued that high social capital generates higher satisfaction and quality of life. For example, social capital increases employee satisfaction (Requena, 2003) public health (Maass, Kloeckner, Lindstrom, \& Lillefjell, 2016) and life satisfaction (Hoogerbrugge \& Berger, 2018). However, the relationship between urban regeneration participation and neighborhood satisfaction is mainly unexplored in urban regeneration research. More studies that examine how community participation in urban regeneration projects affect neighborhood satisfaction are needed for a better understanding of the results of urban regeneration projects and for suggesting more sustainable urban regeneration policies.

Commitment to the community has not escaped criticism. It has been argued that despite the sound understanding of engagement, the evidence base does not support this critical belief in engaging with the mixed results that have been reported. This suggests that apparent and measurable causal benefits cannot be easily recorded (Lawson \& Kearson, 2010). Moreover, it has been suggested by critical community engagement analysts that the practice disguises the growing community's "responsibility", an example of a state that exerts responsibilities on communities that are increasingly expected to take responsibility for their surroundings (Lawson \& Kearson, 2010).

\section{Case study, city of Skenderaj}

For our study, to measure community role in urban regeneration in the city of Skenderaj, we interviewed citizens to whom we addressed nine key questions about public spaces and functions. The selection of the respondents was not intentional and not deliberate. All the participants were residents of the city of Skenderaj. The majority of respondents were male and the rest female. Based on the interviews addressed to different individuals according to the questions listed, we have come to the following conclusions:

Regarding the first question whether there is a special place to develop their activities, most respondents have responded that they didn't think so, but according to them, there is no place to promote activities in the city where they reside. A small part of them said that activities were usually organized in the "Adem Jashari" square that was not suitable for all types of activities, or in the House of Culture "Hasan Prishtina" which does not meet the youth needs for activities, mainly due to the amortization of the facility.

The second question addressed to respondents was whether they had room to watch movies (cinema) and this question received a negative response to the vast majority of respondents. A small part of them said that there was not a good cinema, but there were spaces where the films were shown through the city in some cases, although very rarely and also the movie was shown at the "House of Culture" in Skenderaj, which was not an adequate as an 
environment for watching films. All respondents saw the necessity of building a movie theater in the city.

Another interview question was how much the Municipality invests in the cultural aspect in Skenderaj and if it does enough work in this regard. All the respondents were dissatisfied with this issue and stated that only in some periods, the commune engages in small organizations, but the investments were very weak, and they think that special attention should be given to the cultural aspect in the city.

The dissatisfaction of the respondents emerged and when the fourth question related to finding the necessary materials in the library owned by the city of Skenderaj. Some of them thought the library did not meet the minimum requirements and lacked material and had to supply newer books from all areas of study. Others suggested that the facility should be expanded for the library to serve as an environment for reading not only to attract the materials or books that citizens need. Continuing with the fifth question, on how functional the "House of Culture" is, most respondents responded that it was very partly functional and had many problems as a facility. First, it was not suitable for all kinds of activities. Second, the building was heavily amortized and outdated and needed urgent investment as it did not have the right conditions for young people to develop their activities. The question as to whether there were spaces where young people could develop certain sports some of the respondents said they did not have enough while others suspected that such areas existed but needed to be increased and the existing ones required to be maintained. That such spaces were under construction and hoped that with the completion of the structure, space would be abundant for sporting activities. All the respondents considered it very necessary and very urgent to build a playground where the children of the city could have fun to feel safe and to socialize more with each other by breaking away from the world of technology that has returned in a difficult problem.

The other question addressed to the respondents was whether Skënderaj had sufficient public spaces. The vast majority of respondents thought that the public space was adequate for the population of the city but needed to maintain and adequately planned for the community to use them. While, others thought that public areas were not enough and it would be an excellent municipal policy to offer more, as this would be in the general interest of the community. The last question of the interview was more in a suggested form, on what the community thought should be done to change the current situation, and the main suggestions of the respondents were that spaces that are currently dysfunctional, to become functional and that the municipality to make a priority culture and sport in the city. Others argued that the municipality should increase investment in the town regarding cultural aspects and that the youth should be more active in seeking to improve the conditions of the current facilities and make requests for the enhancement of cultural objects. Another citizen had more concrete thoughts, he suggested that the points discussed in this interview should be put to the discussion table and to prepare a more concrete plan by the municipal authorities. They are allowing the opportunity of all categories of citizens, all ages to share their thoughts about their needs concerning these issues. It is worth noting that a park, renovation of the cinema hall, repair and library material supply are most urgent and should be initially invested in these facilities. In conclusion, according to the community of the city 
Skenderaj, the involvement and the role of the population in urban regeneration it's of high importance.

\section{Conclusions}

As also emphasized by the literature review, a strong need for greater community engagement in urban regeneration is motivated both by the importance of the community factor in itself and by the progressive reduction of the availability of public resources. However, in addition to the theoretical concept, the idea of community role in urban regeneration still needs to be verified to translate into criteria that can be applied. From the conducted interviews we concluded that the city of a study had many problems and the residents were dissatisfied about the social investments and the development of public spaces. For this fact they provided many valuable suggestions for improving the current situation, suggestions that should be taken into account by the local authorities because other studies have shown that in the process of urban re-certification it is necessary cooperation between investors and the community who knows better the cultural heritage values of the city.

To summarize, the main contextual factors to be considered in case studies are:

1) the high level of self-promotion of the local community; long-term community engagement in finding solutions to urban regeneration;

2) enhancing the quality of the socio-economic and physical context of heritage; high level of integration between heritage and urban context;

3) Relevant presence of urban identity elements and a range of other urban identification assets. This can lead to a more sensitive methodology of assessing the urban regeneration initiative that should be able to predict, through discourse, the qualitative contribution of the civic community's role in urban regeneration. However, more knowledge of the quantitative aspects of the suggested factors further can be studied, either through a proxy or by creating some appropriate indicators that will apply to future regeneration initiatives. 


\section{References}

Atkinson, R. (2000). Combating social exclusion in Europe: The new urban policy challenge. Urban Stud. 37, 1037-1055.

Atkinson, R. (2003). Addressing urban social exclusion through community involvement in urban regeneration. In R. Imrie, \& M. Raco, Urban Renaissance? New Labour, Community and Urban Policy (pp. 101120). Bristol: Policy Press.

Bailey, N. (2012). The role, organisation and contribution of community enterprise to urban regeneration policy in the UK. Progress in Planning, 77, 1-35.

Couch, C., Sykes, O., \& Borstinghaus, W. (2011). Thirty years of urban regeneration in Britain, Germany and France: The importance of context and path dependency. Prog. Plan. 75, 1-52.

Dargan, L. (2009). Participation and local urban regeneration: The case of the New Deal for Communities (NDC). Reg. Stud, 305-317.

Davidoff, P. (1965). Advocacy and Pluralism in Planning. Journal of the American Institute of Planners, 31, 331-338.

Fainstein, S. (2014). The just city. Int. J. Urban Sci.18, 1-18.

Hoogerbrugge, M., \& Berger, M. (2018). Neighborhood-based social capital and life satisfaction: The case of Rotterdam. The Netherlands. Urban Geogr.

Jacobs, J. (1961). The Death and Life of Great American Cities. New York: Random House.

Lawson, L., \& Kearson, A. (2010). Community engagement in regeneration: are we getting the point? Journal of Housing and the Built Environment, 19-36.

Maass, R., Kloeckner, C., Lindstrom, B., \& Lillefjell, M. (2016). The impact of neighborhood social capital on life satisfaction and self-rated health: A possible pathway for health promotion? Health Place 42, $120-128$

Magnaghi, A. (2000). Il progetto locale. Torino: Bollati Boringhier.

Moroni, S. (2010). Rethinking the theory and practice of land-use regulation: Towards nomocracy. Plan. Theory , 9, 137-155.

Ombuen, S., Ricci, M., \& Segnalini, O. (2000). I Programmi complessi. Innovazione e Piano nell'Europa delle regione. Milano: Il Sole 24 Ore.

Portugali, J. (2008). Alfasi, N. An approach to planning discourse analysis. Urban Stud , 45, 251-272.

Rabbiosi, C. (2016). City, 20. Urban regeneration 'from the bottom up', 832-844.

Requena, F. (2003). Social capital, satisfaction and quality of life in the workplace. Soc. Indic. Res, 61, 331360.

Ricci, M., \& Avarello, P. (2000). Dai programmi complessi alle politiche integrate di sviluppo urbano. Roma: INU Edizioni. 